\title{
Modelling surface run-off and trends analysis over India
}

\author{
P K Gupta ${ }^{1, *}$, S Chauhan ${ }^{2}$ and M P OzA ${ }^{1}$ \\ ${ }^{1}$ Space Applications Centre, Indian Space Research Organisation, Ahmedabad, India. \\ ${ }^{2}$ Anand Agriculture University, Anand, India. \\ *Corresponding author. e-mail: pkgupta@sac.isro.gov.in
}

The present study is mainly concerned with detecting the trend of run-off over the mainland of India, during a time period of 35 years, from 1971-2005 (May-October). Rainfall, soil texture, land cover types, slope, etc., were processed and run-off modelling was done using the Natural Resources Conservation Service (NRCS) model with modifications and cell size of $5 \times 5 \mathrm{~km}$. The slope and antecedent moisture corrections were incorporated in the existing model. Trend analysis of estimated run-off was done by taking into account different analysis windows such as cell, medium and major river basins, meteorological sub-divisions and elevation zones across India. It was estimated that out of the average $1012.5 \mathrm{~mm}$ of rainfall over India (considering the study period of 35 years), $33.8 \%$ got converted to surface run-off. An exponential model was developed between the rainfall and the run-off that predicted the run-off with an $R^{2}$ of 0.97 and RMSE of $8.31 \mathrm{~mm}$. The run-off trend analysed using the Mann-Kendall test revealed that a significant pattern exists in 22 medium, two major river basins and three meteorological subdivisions, while there was no evidence of a statistically significant trend in the elevation zones. Among the medium river basins, the highest positive rate of change in the run-off was observed in the Kameng basin $(13.6 \mathrm{~mm} / \mathrm{yr})$, while the highest negative trend was observed in the Tista upstream basin $(-21.4$ $\mathrm{mm} / \mathrm{yr}$ ). Changes in run-off provide valuable information for understanding the region's sensitivity to climatic variability.

\section{Introduction}

Water resources have become a prime concern for any development and planning including food production, flood control and effective water resource management. Surface run-off, which is the water that occurs when the soil is infiltrated to full capacity and excess water from rain flows over the land, is a major component of the water cycle. The spatio-temporal variation of hydrological variables responsible for run-off generation plays a major role in run-off modelling at region scales. Remote sensing, GIS and advancement of the computer technology based evaluation of land surface properties at spatial and temporal scales are very useful input data for hydrological models. Using remote sensing data is not only technically viable, but also provides a good fit of technologies to maximise the value of available spatial data (Jobin and Pultz 1997). According to Kite and Piteroniro (1996), the benefit/cost ratio ranging from $75: 1$ to 100:1 can be realised by using remotely sensed data in hydrology and water resources management.

Rainfall run-off models are grouped into three categories, namely: empirical black-box, lumped conceptual and distributed physically-based modelling systems. The majority of the rainfall run-off modelling systems, used in practice are from the first two categories (Refsgaard and Storm 1995; Beven 2000; Singh et al. 2006). Empirical blackbox models are entirely lacking explicitly and welldefined representations of the physical processes

Keywords. Run-off; curve number; Mann-Kendall test; medium river basin. 
involved in the transformation of rainfall into a run-off. There are only a few distributed physically based hydrologic modelling systems suitable for research purposes and for real world projects but these are highly data intensive. Conceptual rainfall run-off models are designed to approximate (in some physically realistic manner) the general internal subprocesses and physical mechanisms which govern the hydrologic cycle. Therefore, conceptual models are most suitable for regional scale hydrological modelling with reasonably good accuracy.

The sensitivity of the run-off to changes in precipitation and other climate parameters is well documented (Sharma et al. 2001; Chatterjee et al. 2001; Pandey et al. 2003; Zade et al. 2005; Gupta and Panigrahy 2007; Gupta et al. 2011, 2012); hence, it is necessary to investigate whether estimated run-off records exhibit evidence of increasing/ decreasing trends that may be linked to climate change and impact on the hydrological cycle, which could eventually lead to shifts in the availability of surface water. Therefore, proper statistical investigation of the existence of such trends is paramount.

Information on spatial and temporal variations of run-off is, thus, important in understanding the surface water on a regional scale. The present study focuses on modelling the surface run-off with the integration of remote sensing derived parameters during monsoon period (May-October) of 19712005. Conceptual modified Natural Resources Conservation Service (NRCS) (Burges et al. 1998) along with Mann-Kendall test have been used together with the Sen's slope estimator for the determination of rainfall and run-off trends and slope magnitude over various analysis windows. The study was done at daily time step with the cell size of $5 \times 5 \mathrm{~km}$.

\section{Study area}

Mainland (excluding Andaman and Nicobar and Lakshadweep islands) of India has been used as the study area. Geographically, India is situated at $6^{\circ} 46^{\prime} \mathrm{N}$ to $37^{\circ} 5^{\prime} \mathrm{N}$ and $68^{\circ} 6^{\prime} \mathrm{E}$ to $97^{\circ} 25^{\prime} \mathrm{E}$. Over $80 \%$ of the annual rainfall is received in the four rainy months of June-September. Pre-monsoon and post-monsoon rains are general phenomena experienced year to year during the month of May and October, respectively and affect the antecedent moisture conditions, which is eventually responsible for the quantification of the run-off. Therefore, in the present study, May-October period has been selected.

Presently, considering the average annual rainfall along with total snowfall and glacier melt in terms of volume works out to about 4000 billion cubic meters (bcm). However, due to losses, water availability in the country has been assessed to be $1869 \mathrm{bcm}$. Even this available water cannot be fully utilised due to topographical constraints and hydrological features and utilisable water has been estimated $1123 \mathrm{bcm}$ comprising of $690 \mathrm{bcm}$ of surface water and $433 \mathrm{bcm}$ of replenishable ground water (Mall et al. 2006). The per capita availability of water in 1951 was assessed to be $5177 \mathrm{~m}^{3}$. Due to increase in population, urbanisation and industrialisation, this has come down to about $1650 \mathrm{~m}^{3}$ (water stress condition) and by the year 2025, it would be 1450, approaching towards water scarcity zone (1200). Also, a warmer climate leads to higher rates of evaporation and increase in liquid precipitation. Due to this flood magnitude and frequency are likely to increase in many regions, and low flows are to decrease. This could be a major blow to surface water reserves in terms of both quality and quantity. In India, most of the studies are confined to the determination of trends in the rainfall at national and regional scales. Only limited work has been done to analyse dynamic hydrological variables such as the run-off. In the present study, many analysis windows such as major and medium river basins, agro-climatic zones, meteorological sub-divisions, elevation zones, etc., have been applied, and changes in the run-off along with trends and its magnitude have been studied for 35 years period (1971-2005). Thus, the present study is a substantial improvement over the work carried out previously.

\section{Data used}

\subsection{Remote Sensing Data}

\subsubsection{Slope (ASTER DEM)}

The elevation data was obtained from ASTER (Advanced Space borne Thermal Emission \& Reflection Radiometer). The mean elevation of India was estimated to be $720.9 \mathrm{~m}$ with standard deviation 1200.4 and coefficient of variability 1.71 , while the maximum elevation goes up to $8238 \mathrm{~m}$. The elevation map was converted to a slope map in the GIS environment for the application in the curve number model. Average slope, standard deviation and CV were estimated to be $3.68 \%, 7.81 \%$ and $2.1 \%$, respectively, over India.

\subsubsection{Land use land cover (AWiFS-Resourcesat-2, $N R D B)$}

The temporal Advanced Wide Field Sensor (AWiFS) data based LULC map from Natural Resources Data Base of Space Application Centre (NRDB/SAC) was used (figure 1). It has 17 land cover classes. Agriculture and forest cover types 


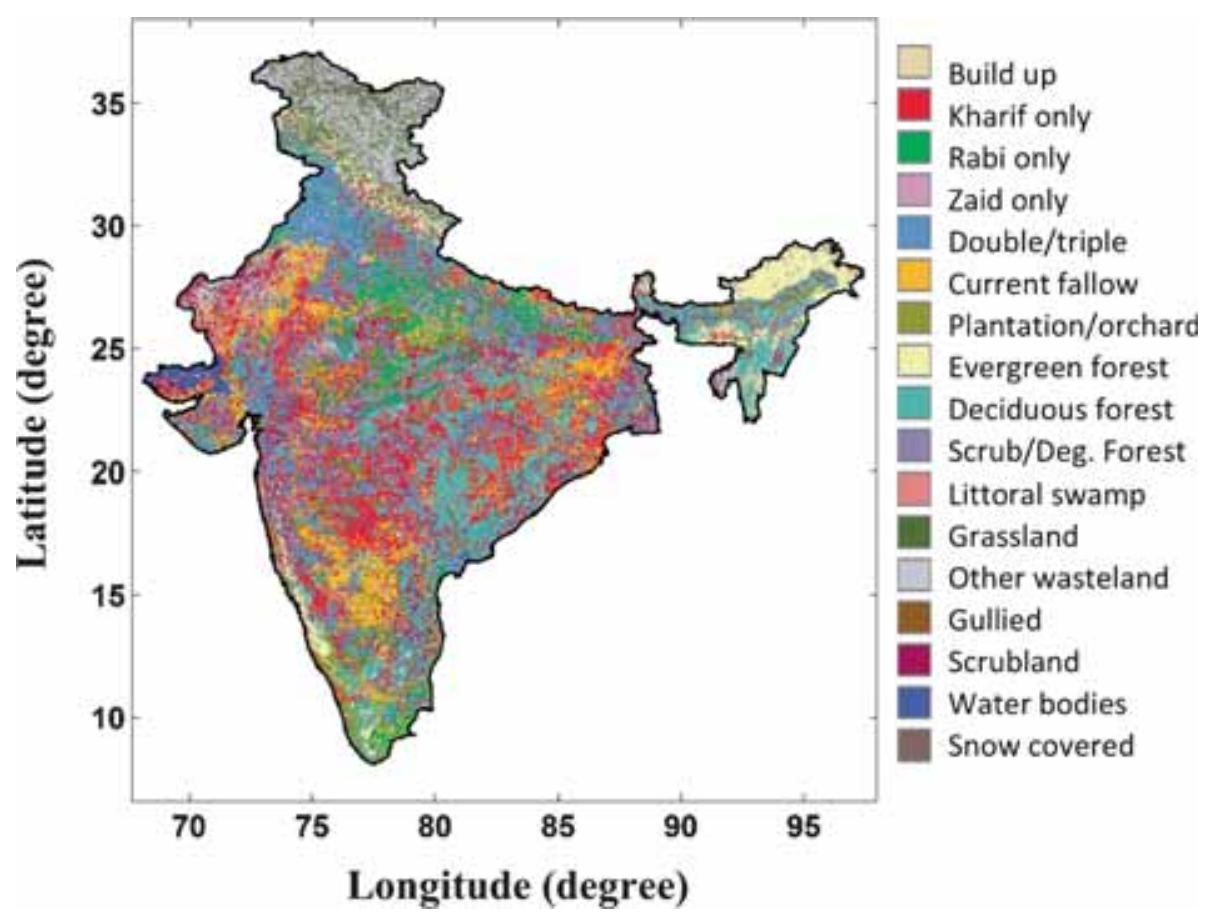

Figure 1. Land use land cover map of India (derived using AWiFS data).

were further classified such as good, fair and poor classes based on the 10-day composite NDVI data (SPOT-VGT) (Zade et al. 2005).

\subsection{Other data}

\subsubsection{Rainfall (IMD)}

Daily rainfall data archived from the India Meteorological Department over India, with the grid size $(0.5 \times 0.5$ degree $)$, for the period 1971-2005, has been used to carry out the analysis. The dataset has been developed using daily rainfall data from more than 6000 stations over India (Rajeevan and Bhate 2009).

\subsubsection{Soil (NBSS_LUP)}

Soil texture map is taken from National Bureau of Soil Survey and Land Use Planning (NBSS_LUP) of India. Fourteen soil textures have been obtained over India. Soil textural classes were used to prepare Hydrological Soil Group (HSG) map considering the soil infiltration and drainage characteristics of different soils (A-D; high to low infiltration and low to high run-off). All the above data were resampled to $5 \times 5 \mathrm{~km}$ grid cells in the GIS environment.

\section{Methodology}

Curve number model for run-off estimation, Mann-Kendall for trend and Theil Sen's slope estimator for the rate of change of run-off have been used. Detailed methodology is given in figure 2 .

\subsection{NRCS-CN method}

The Soil Conservation Service Curve Number (SCS-CN) method is a rainfall run-off model, widely used to convert rainfall to rainfall-excess using the curve number, which is derived from watershed physical characteristics and 5-day antecedent rainfall. The SCS-CN method has been used in the developed model. The curve number method (USDA 1986), also known as the hydrologic soil cover complex method, is a versatile and widely used procedure for run-off estimation. SCS method involves the relationship of land cover description, hydrologic soil group and curve number. Hydrologic soil group is obtained from the type of soil (Chow et al. 1988). Curve number for antecedent moisture condition (AMC) II, CN2, first needs to be determined from the standard table (SCS 1986) using land cover type and hydrologic soil group. Curve number for AMC-I and AMC-III (CN1 and CN3) can then be estimated from $\mathrm{CN} 2$ values.

AMC is calculated based on the accumulation of previous 5 days rainfall. $\mathrm{AMC}$ is categorised into three levels, AMC-I, AMC-II and AMC-III. AMCI refers to the dry condition, AMC-II to the normal or average condition and AMC-III to the wet condition of the watershed. The higher the antecedent moisture or rainfall amount, the higher is $\mathrm{CN}$ and, therefore, the run-off potential of the watershed and vice versa. 


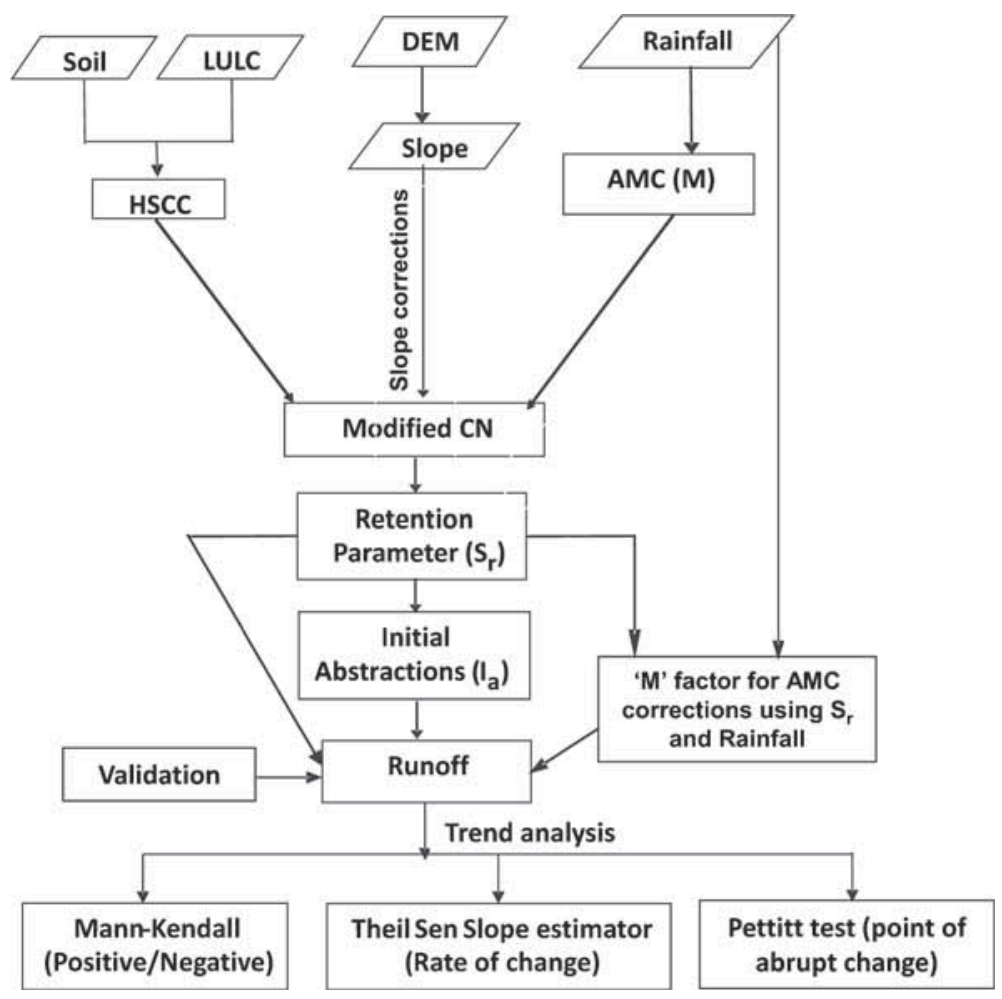

Figure 2. Methodology for run-off modelling and trend analysis.

For dry conditions (AMC-I): $0<$ rainfall previous 5 days $\leq 35 \mathrm{~mm}$

For normal conditions (AMC-II): $35<$ rainfall previous 5 days $\leq 52.5 \mathrm{~mm}$

For wet conditions (AMC-III): rainfall previous 5 days $>52.5 \mathrm{~mm}$

The NRCS-CN method is based on the water balance equation and two fundamental hypotheses which can be expressed as:

$$
\begin{gathered}
P=I_{a}+F+Q, \\
\frac{Q}{P-I_{a}}=\frac{F}{S_{r}}
\end{gathered}
$$

and

$$
I_{a}=\lambda S_{r}
$$

where $P$ is the total precipitation, $I_{a}$ is the initial abstraction, $F$ is the cumulative infiltration, $Q$ is the direct run-off, $S_{r}$ is the potential maximum retention, and $\lambda$ is the initial abstraction coefficient.

Combination of equations ( 1 and 2 ) leads to the popular form of the existing NRCS-CN method:

$$
Q=\frac{\left(P-I_{a}\right)^{2}}{\left(P+I_{a}-S_{r}\right)} .
$$

Parameter $S_{r}(\mathrm{~mm})$ in equation (4) is expressed as:

$$
S_{r}=\left(\frac{25400}{C N_{s}}-254\right)
$$

with $\lambda=0.2$ (existing NRCS-CN method), substitution of equation (3) into equation (4) yields the $S$-values for different $P-Q$ sets, and these $S_{r}$ values are converted to $\mathrm{CN}$ values using equation (5). However, the effect of slope has not been taken into account in this method.

\subsubsection{Slope correction}

The land slope is an important factor determining water movement within a landscape. Previous studies have shown that the surface run-off increases as the slope increases which can be explained by the following:

(1) a reduction of the initial abstraction (Huang 1995; Chaplot and Bissonnais 2003),

(2) a decrease in infiltration,

(3) a reduction of the recession time of overland flow.

The old model assumes a constant slope of $5 \%$ but at regional scales, the slope variations are large. Therefore, using the Sharpley and Williams (1990) approach, the slope adjusted $\mathrm{CN}_{2}$, named $\mathrm{CN}_{2 \mathrm{~s}}$, is obtained by

$$
\mathrm{CN}_{2 \mathrm{~s}}=1 / 3\left(\mathrm{CN}_{3}-\mathrm{CN}_{2}\right)\left(1-2 \mathrm{e}^{-13.86 \mathrm{~s}}\right)+\mathrm{CN}_{2},
$$


where,

$$
\mathrm{CN}_{3}=\mathrm{CN}_{2} \mathrm{e}^{0.00673\left(100-\mathrm{CN}_{2}\right)}
$$

Here, $\mathrm{CN}_{2}$ and $\mathrm{CN}_{3}$ are the SCS-CN for soil moisture conditions 2 (average) and 3 (wet), and $\mathrm{s}\left(\mathrm{mm}^{-1}\right)$ is the soil slope. $\mathrm{CN}_{2 \mathrm{~s}}$ is then used, instead of $\mathrm{CN}_{2}$, in the subsequent calculations of the run-off volume.

Slope adjusted curve numbers for moisture conditions I $\left(\mathrm{CN}_{1 \mathrm{~s}}\right)$ and III $\left(\mathrm{CN}_{3 \mathrm{~s}}\right)$ are calculated using the following relationships (Haith et al. 1996):

$$
\mathrm{CN}_{1 \mathrm{~s}}=\frac{4.2 \mathrm{CN}_{2 \mathrm{~s}}}{10-0.058 \mathrm{CN}_{2 \mathrm{~s}}}
$$

and

$$
\mathrm{CN}_{3 \mathrm{~s}}=\frac{23 \mathrm{CN}_{2 \mathrm{~s}}}{10+0.13 \mathrm{CN}_{2 \mathrm{~s}}}
$$

where $\mathrm{CN}_{1 \mathrm{~s}}$ and $\mathrm{CN}_{3 \mathrm{~s}}$ are slope adjusted curve numbers for AMC-I (dry) and AMC-III (wet) conditions, respectively. The value of $\mathrm{CN}$ would range from 0 to 100 .

\subsubsection{Antecedent moisture corrections}

The old model uses a large range of rainfall values for the estimation of antecedent moisture conditions that introduces sudden jumps in the wetness conditions. Therefore, using the concept of $C=S_{r}$, where $C$ is the run-off coefficient $\left(=Q /\left(P-I_{a}\right)\right)$ and $S_{r}=$ degree of saturation, Mishra et al. (2005) modified equation (2) for antecedent moisture $M$ as:

$$
\frac{Q}{P-I_{a}}=\frac{F+M}{S_{r}+M},
$$

which, upon substitution into equation (1) leads to

$$
Q=\frac{\left(P-I_{a}\right)\left(P-I_{a}+M\right)}{\left(P+I_{a}+S_{r}+M\right)} .
$$

Here, $M$ is computed as:

$$
M=0.5\left[-S_{r}+\sqrt{S_{r}^{2}+4 P_{5} S_{r}}\right],
$$

where $P_{5}$ is the antecedent 5-day precipitation amount.

Also, the condition $P_{5} \geq 0$ and $P \geq I_{a}$ must be satisfied.

\subsection{Mann-Kendall test (MK)}

By MK test, we want to test the null hypothesis $H_{0}$ of no trend, i.e., the observations $x_{i}$ are randomly ordered in time, against the alternative hypothesis, $H_{A}$, where there is an increasing or decreasing monotonic trend. MK test (Kendall 1962) provides a non-parametric method to detect the existence of a trend in a time series data. The data values are evaluated as an ordered time series. Each data value is compared with all subsequent data values. If a data value from a later time period is higher than a data value from an earlier time period, the statistic $S$ is incremented by 1 . On the other hand, if the data value from a later time period is lower than a data value sampled earlier, then $S$ is decremented by 1 . The net result of all such increments and decrements yields the final value of $S$. The MK test statistic $S$ is calculated using the formula

$$
S=\sum_{k=1}^{n-1} \sum_{j=k+1}^{n} \operatorname{sgn}\left(x_{j}-x_{k}\right),
$$

where

$$
\operatorname{sgn}\left(x_{j}-x_{k}\right)=\left\{\begin{array}{ll}
+1 & \text { if } x_{j}-x_{k}>0 \\
0 & \text { if } x_{j}-x_{k}=0 \\
-1 & \text { if } x_{j}-x_{k}<0
\end{array} .\right.
$$

Here, $x_{j}$ and $x_{k}$ are the annual values in years $j$ and $k(j>k)$ respectively.

The mean and variance of $S$, under the assumption of the null hypothesis (no trend in time series data), are given by

$$
\begin{aligned}
& E(S)=0 \\
& \operatorname{Var}(S)=\left\{\begin{array}{cl}
\frac{\{n(n-1)(2 n+5)}{\left.-\sum_{j=1}^{p} t_{j}\left(t_{j}-1\right)\left(2 t_{j}+5\right)\right\}} & \text { if ties } \\
\frac{\{n(n-1)(2 n+5)\}}{18} & \text { if no ties }
\end{array}\right.
\end{aligned}
$$

The standard test statistic, $Z$, is computed as follows:

$$
Z=\left\{\begin{array}{ll}
\frac{S-1}{\sqrt{\operatorname{VAR}(S)}} & \text { if } S>0 \\
0 & \text { if } S=0 \\
\frac{S+1}{\sqrt{\operatorname{VAR}(S)}} & \text { if } S<0
\end{array} .\right.
$$

If $n$ (number of years) is lesser than 10, the value of $|S|$ is compared directly to the theoretical distribution of $S$ derived by Mann and Kendall (Gilbert 1987). The two-tailed test is used. At a certain probability level $\alpha, H_{0}$ is rejected in favour of $H_{A}$ if the absolute value of $S$ equals or exceeds a specified value $S_{\alpha / 2}$, where $S_{\alpha / 2}$ is the smallest $S$ which has a probability of less than $\alpha / 2$ under $H_{0}$. A positive (negative) value of $S$ indicates an upward (downward) trend. For $n \geq 10$, the statistic $S$ is approximately normally distributed with the mean and variance as follows:

$$
E(S)=0 .
$$

The presence of a statistically significant trend is evaluated using the $Z$ value. A positive (negative) value of $Z$ indicates an upward (downward) trend. 
To test for either an upward or downward monotone trend (a two-tailed test) at $\alpha$ level of significance, $H_{0}$ is rejected if the $|Z|>Z_{(1-\alpha / 2)}$, where $Z_{(1-\alpha / 2)}$ is obtained from the standard normal cumulative distribution tables.

\subsection{Sen's slope estimator}

If a linear trend is present in a time series, then the slope (change per unit time) can be estimated by using a nonparametric procedure developed by Sen (1968). This means that linear model $f(t)$ can be described as:

$$
f(t)=Q t+B
$$

where $Q$ is the slope and $B$ is a constant.

To derive an estimate of the slope $Q$, the slopes of all data pairs are calculated:

$$
Q_{i}=\frac{x_{i}-x k}{j-k}, \quad i=1,2,3, \ldots, N, j>k
$$

If there are $n$ values of $x_{j}$ in the time series, we get as many as $N=n(n-1) / 2$ slope estimates of $Q_{i}$. The Sen's estimator of slope is the median of these $N$ values of $Q_{i}$. The $N$ values of $Q_{i}$ are ranked from the smallest to the largest and the Sen's estimator is:

$$
Q=\left\{\begin{array}{ll}
Q_{\frac{N+1}{2}} & \text { if } N \text { is odd } \\
\frac{1}{2}\left(Q_{\frac{N}{2}}+Q_{\frac{N+2}{2}}\right) & \text { if } N \text { is even }
\end{array} .\right.
$$

A $100(1-\alpha) \%$ two-sided confidence interval about the slope estimate is obtained by the nonparametric technique based on the normal distribution. The method is valid for $n$ as small as 10 unless there are many ties. Positive value of $Q_{i}$ indicates an upward or increasing trend and a negative value of $Q_{i}$ gives a downward or decreasing trend in the time series.

\subsection{Pettitt test}

A non-parametric test to determine the point of abrupt change in a time series data is given by Pettitt (1979). It is based on the ranks of the time series data. It is briefly described here.

Assume that, for a time series of data $x_{1}, x_{2}, \ldots$, $x_{t-1}, x_{t}, x_{t+1}, \ldots, x_{T}$, the break point is at time $t$ (i.e., value $x_{t}$ ). The test statistic is given by

$$
U_{t, T}=\sum_{i=1}^{t} \sum_{j=t+1}^{T} \operatorname{sgn}\left(x_{i}-x_{j}\right) ;
$$

where the sgn function is defined as in equation (13).

Let $\mathrm{KT}=\max \left|U_{t, T}\right|$. The significant level associated with $\mathrm{KT}$ is approximately determined by $\rho=\exp \left[-6 \mathrm{KT}^{2} /\left(\mathrm{T}^{2}+\mathrm{T}^{3}\right)\right] \rho$. If $\rho$ is smaller than specified significance level, the null hypothesis is rejected.

\section{Analysis windows}

River basin is considered as the basic hydrological unit for planning and development of water resources. A total of 28 river basins have been classified as the major river basins in India. The corresponding names of the basins are given in table 1 . There are 12 major river basins with catchment area of $20,000 \mathrm{~km}^{2}$ and above. The total catchment area of these rivers is 25.3 lakh $\mathrm{km}^{2}$. The major river basin is the Ganga-Brahmaputra-Meghna, which is the largest with catchment area of about 11.0 lakh $\mathrm{km}^{2}$ (more than $43 \%$ of the catchment area of all the major rivers in the country). The other major river basins with catchment area more than 1.0 lakh $\mathrm{km}^{2}$ are Indus, Mahanadi, Godavari and Krishna.

Medium river basins, total 190 have been delineated using DEM across India. There are 46 medium river basins with catchment area between 2000 and $20000 \mathrm{~km}^{2}$. The total catchment area of medium river basins is about 2.5 lakh $\mathrm{km}^{2}$. All major river basins and many medium river basins are inter-state in nature which covers about $81 \%$ of the geographical area of the country.

For the purpose of rainfall, the country has been divided into 34 meteorological sub-divisions (table 1). The resource potential of the country, which occurs as a natural run-off in the rivers, is about $1869 \mathrm{~km}^{3}$ as per the basin-wise latest estimates of the Central Water Commission, considering both surface and ground water as one system.

Moving to coarser scale, the analysis was implemented for 14 agro-climatic regions as defined by Planning Commission of India (Island region was left out) considering mainland of India. Area varies from $393,714 \mathrm{~km}^{2}$ (Southern Plateau and Hills Region) to $65,913 \mathrm{~km}^{2}$ (Lower Gangetic Plain region).

India was divided into 11 elevation zones with $100 \mathrm{~m}$ equal interval up to $1000 \mathrm{~m}$ with last class (11th elevation zone) greater than $1000 \mathrm{~m}$ and the run-off analysis is done on these zones in order to determine the variability in the run-off as the magnitude of the elevation changes.

\section{Results and discussion}

The results for run-off were extracted at the national scale as well as for different analysis windows such as major river basins, meteorological sub-divisions, medium river basins, elevation zones, etc. The estimated run-off results have been validated with the available data for the river basins from the river discharge database provided by the Center for Sustainability and the Global 
Table 1. Average run-off and rate of change considering 1971-2005 time period over major river basins and met-subdivisions of India.

\begin{tabular}{|c|c|c|c|c|c|}
\hline Major river basin & Run-off (mm) & $\mathrm{T}$ & Meteorological subdivisions & Run-off (mm) & $\mathrm{T}$ \\
\hline Indus and others & 99.0 & 26.2 & Arunachal Pradesh & 667.5 & -78.5 \\
\hline Ganga & 344.9 & -21.8 & Assam \& Meghalaya & 955.5 & 226.1 \\
\hline Brahmaputra & 733.5 & 5.5 & NMMT & 526.7 & -9.9 \\
\hline Between Indus and Luni & 25.3 & -2.2 & SHWB \& Sikkim & 945.1 & -149.9 \\
\hline Tista and others & 918.2 & -157.0 & Gangetic West Bengal & 538.0 & 42.2 \\
\hline Luni & 89.5 & 7.6 & Odhisa & 448.6 & 38.6 \\
\hline Chindwin and others & 769.9 & 164.4 & Jharkhand & 477.8 & -28.1 \\
\hline Gujrat minor rivers & 215.2 & 4.0 & Bihar & 486.9 & -34.2 \\
\hline Sabarmati & 287.6 & 24.6 & East UP & 421.4 & -61.3 \\
\hline Damodar and others & 553.5 & 53.2 & West U & 332.4 & 22.9 \\
\hline Mahi & 329.9 & -22.2 & Uttarakhand & 281.2 & 109.3 \\
\hline Narmada & 440.4 & -42.0 & Haryana, Chd \& Delhi & 144.1 & -16.7 \\
\hline Brahmani & 473.1 & 35.9 & Punjab & 189.8 & -38.7 \\
\hline Mahanadi & 418.9 & 4.6 & Himachal Pradesh & 217.1 & 64.4 \\
\hline Subernarekha & 457.7 & -90.4 & $\mathrm{~J} \& \mathrm{~K}$ & 57.0 & 25.4 \\
\hline Godavari & 377.8 & 58.8 & West Rajasthan & 49.7 & 1.4 \\
\hline Baitrani & 485.3 & 16.0 & East Rajasthan & 227.3 & -63.6 \\
\hline Tapi & 285.9 & 27.5 & West MP & 372.0 & -74.5 \\
\hline WSCR & 899.1 & -3.4 & East MP & 456.0 & -55.8 \\
\hline BGM & 346.5 & 26.3 & Saurashtra \& Kutch & 359.9 & 37.2 \\
\hline Krishna and others & 291.9 & -3.1 & Gujarat region & 194.0 & 40.8 \\
\hline BGK1 & 256.2 & 12.1 & Konkan \& Goa & 1256.5 & 3.0 \\
\hline BGK2 & 212.7 & 44.7 & Madhya Maharashtra & 433.6 & 62.2 \\
\hline BKC1 & 243.4 & -78.2 & Marathwada & 243.6 & 99.3 \\
\hline BKC2 & 170.6 & -33.4 & Vidarbha & 364.7 & 37.7 \\
\hline Cauvery & 197.5 & -61.7 & Chattisgarh & 440.0 & -4.4 \\
\hline BKC3 & 190.3 & -60.4 & Coastal Andhra Pradesh & 265.9 & 48.5 \\
\hline \multirow[t]{7}{*}{$\mathrm{BKC} 4$} & 155.8 & -73.7 & Telangana & 293.7 & 44.0 \\
\hline & & & Rayalaseema & 155.4 & 11.9 \\
\hline & & & TN \& Pondicherry & 182.9 & -23.4 \\
\hline & & & Coastal Karnataka & 1985.5 & -44.7 \\
\hline & & & NI Karnataka & 239.4 & -12.0 \\
\hline & & & SI Karnataka & 361.5 & -105.9 \\
\hline & & & Kerala & 855.0 & -129.7 \\
\hline
\end{tabular}

*BKC: Between Krishna and Cauvery; BGM: Between Godavari and Mahanadi; BGK: Between Godavri and Krishna and WSCR: West South Coast Rivers.

Environment (SAGE). Run-off trends were also analysed for the above-mentioned analysis windows and also for India as a whole.

\subsection{Variability of the rainfall over India during 1971-2005}

The rainfall analysis was done for the season MayOctober for the year 1971-2005. There is no significant particular trend in the rainfall pattern over India for the period 1971-2005. Kumar et al. (2010) concluded that there is no significant trend over India for seasonal, annual and monthly scales using 135 years data (1871-2005). Srivastava et al. (1992) showed that the mean monsoon seasonal rainfall has not changed significantly in the past century. Similar results have been found by Mooley and Parthasarathy (1984), Sarkar and Thapliyal (1988), Thapliyal and Kulshreshtha (1991), Lal (2001) and Sinha Ray and De (2003). The total mean rainfall amount over the years ranged from 792.7 to $1307.5 \mathrm{~mm}$, lowest being in the year 1972 while the highest was in the year 2005. Index for the spatial variability (coefficient of variability; CV) of rainfall was also calculated. High value of $\mathrm{CV}$ indicates high temporal variability and vice versa. Lowest (0.62) and highest (1.06) values of index were obtained for the year 1996 and 1974, respectively. Maximum and minimum positive anomalies were of 295.0 and $7.54 \mathrm{~mm}$ for the years 2005 and 2003, respectively whereas negative anomalies vary 
from -219.7 to $-3.48 \mathrm{~mm}$ for the years 1972 and 2004, respectively.

\subsection{Run-off analysis over India}

The run-off tend to be in proportion to the precipitation amount that was witnessed in that particular year. Like rainfall, there is also no clear significant trend in average seasonal run-off over the country. The run-off amount ranged from 527.3 to $256.4 \mathrm{~mm}$, highest being in the year 2005, which accounted for the $40.3 \%$ of the mean rainfall in that year and the lowest being in the year 1972, which accounted for $32.3 \%$ of the mean rainfall in the respective year. Figure 3 represents the rainfall and run-off anomaly. Run-off anomaly varies from -85.2 to $185 \mathrm{~mm}$ for the year 1973 and 2005, respectively. Lowest (1.16) and highest (1.95) value of CV was obtained for the year 1996 and 1974, respectively (figure 4 ).

\subsection{Rainfall vs. run-off}

A relationship between the independent variable, i.e., the seasonal rainfall and the dependent variable, i.e., the run-off has been developed taking in to account 35 years data. As the amount of rainfall increases, the run-off produced also increases but not at the same pace. A non-linear curve has been fitted to the rainfall and run-off. The exponential curve with second order has proved to be the best fit. Thus, a general model has been developed:

$$
f(x)=a * \exp (b * x)+c * \exp (d * x) .
$$

Coefficients $a=103.7, b=0.001166, c=3529 e-15$, $d=0.02846$. The $R^{2}$ value is 0.97 and it assesses how well a model explains and predicts future outcomes. It is indicative of the level of explained variability in the model. Root mean square error was of $8.31 \mathrm{~mm}$. The overall rainfall to run-off conversion (run-off coefficient) value in the 35 years has been found 0.34 .

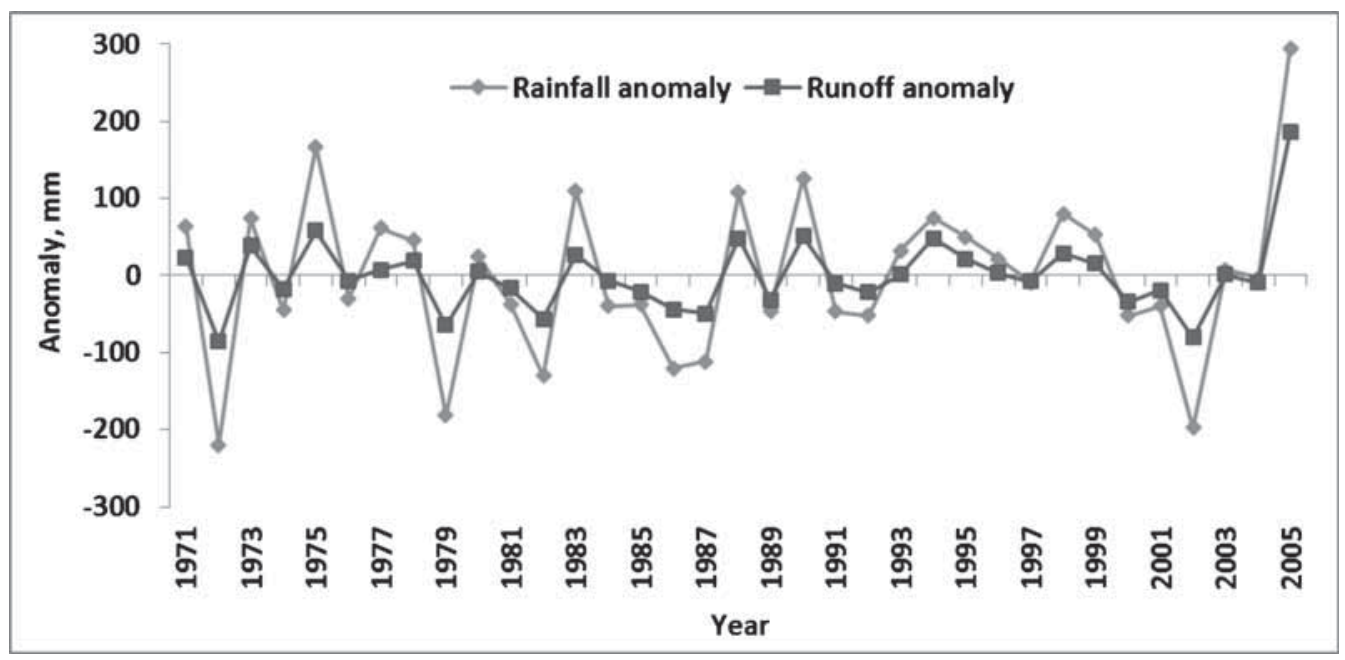

Figure 3. Rainfall and run-off anomaly over India during the study period (1971-2005).

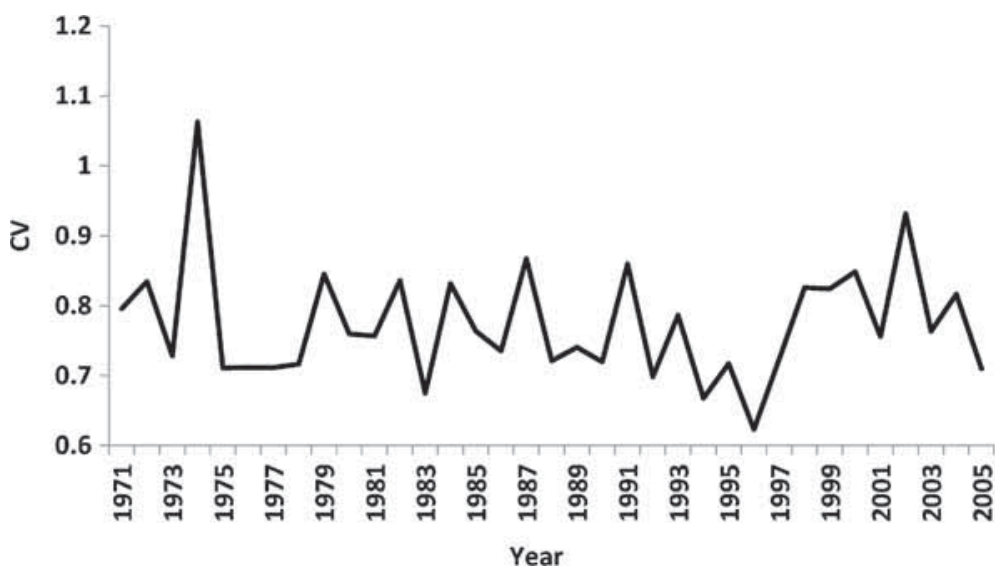

Figure 4. Coefficient of variability for run-off over India during 1971-2005. 


\subsection{Average rainfall and run-off over 35 years}

Average run-off and run-off coefficient in 35 years are shown in figure 5 . The concentration of the rainfall amount appears to be lesser in the northwestern (Oza and Kishtwal 2014) and some of the southern parts of the country while the western peninsula along with the Himalayan belt and the eastern part of the country have witnessed heavy rain in the last 35 years. The mean rainfall of 35 years has been $1012.5 \mathrm{~mm}$ while the standard deviation was 778.6 $\mathrm{mm}$. The similar trend is observed in the run-off, while the mean associated run-off was $341.6 \mathrm{~mm}$ with the standard deviation of $469.5 \mathrm{~mm}$.

\subsection{Validation}

The modelled run-off data was validated using the discharge data of some of the rivers from the Global River Discharge Database provided by the Center for Sustainability of Global Environment which contains a compilation of monthly mean river discharge data (http://www.sage.wisc. edu/riverdata). This site contains a compilation of monthly mean river discharge data for over 3500 sites worldwide. The data sources are RivDis2.0, the United States Geological Survey, Brazilian National Department of Water and Electrical Energy, and HYDAT-Environment Canada. The period of record for each station is variable. The validation was done for the major river basins like the Ganga, Narmada and Mahi (figure 6). A reasonably good relationship has been established between the modelled and measured data which confirms that the run-off data modelled in the study is accurate to a great extent. Consideration of annual changes in the LULC may yield more accurate results at the finer scales, but for regional scales, it will not affect much. This study is limited by the regional analysis rather going macro-watershed scales which otherwise demands the physically-based modelling approach.

\subsection{Trend analysis}

Trend analysis over the mainland of India was done considering 35 years of run-off data from 1971 to 2005 (May-October). Mann-Kendall and Sen's Slope estimator were used for the determination of the trend in run-off across India. Also, run-off trends were analysed for various analysis windows such as river basins, met sub-divisions, agro-climatic regions, over India as a whole and elevation zones.

Figure 7 shows $Z$ and $T$ statistics variability over India. In figure 7 , regions, where the $Z$ value is above 1.64 or below -1.64 , are also marked, which denotes the significant trend in the run-off pattern. This is increasing, mainly, in the north belt and adjoining parts of peninsular India and decreasing in the westcentral and northwestern regions. The rate of change in run-off has been distributed in the range of -300 to $300 \mathrm{~mm}$; mainly the northeast belt (downstream of Brahmaputra basin), part of central north-east, west, and southern peninsular India experienced remarkable changes in the run-off which is above $150 \mathrm{~mm}$ over the 35-year time period. Run-off trends are not in sync with the rainfall which shows decreasing (Vijay et al. 2010) pattern except peninsular India where both parameters are increasing. It has been observed that concentration of heavy rainfall events (rainfall between 100 and $150 \mathrm{~mm}$ in a day) has increased
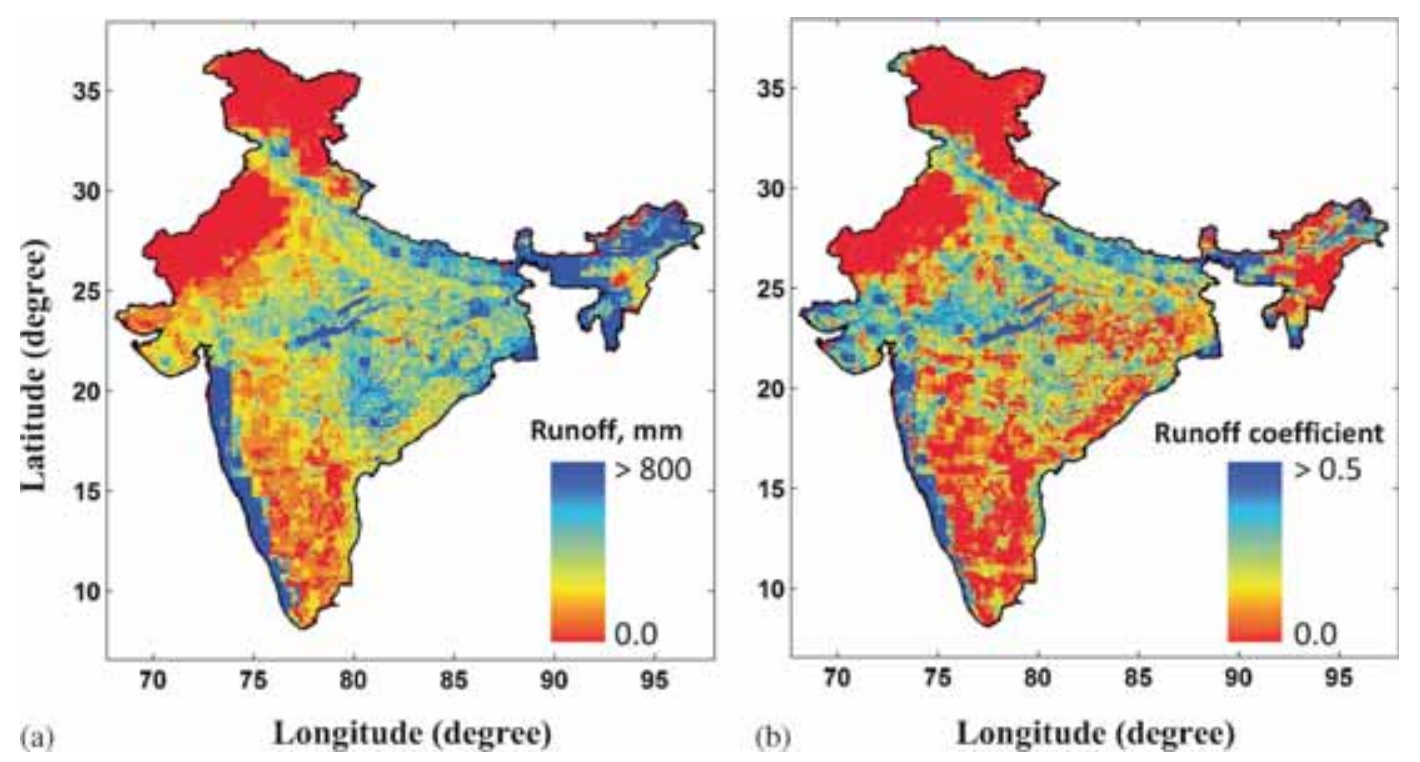

Figure 5. (a) Average run-off (mm) and (b) run-off coefficient over India considering 1971-2005 period. 

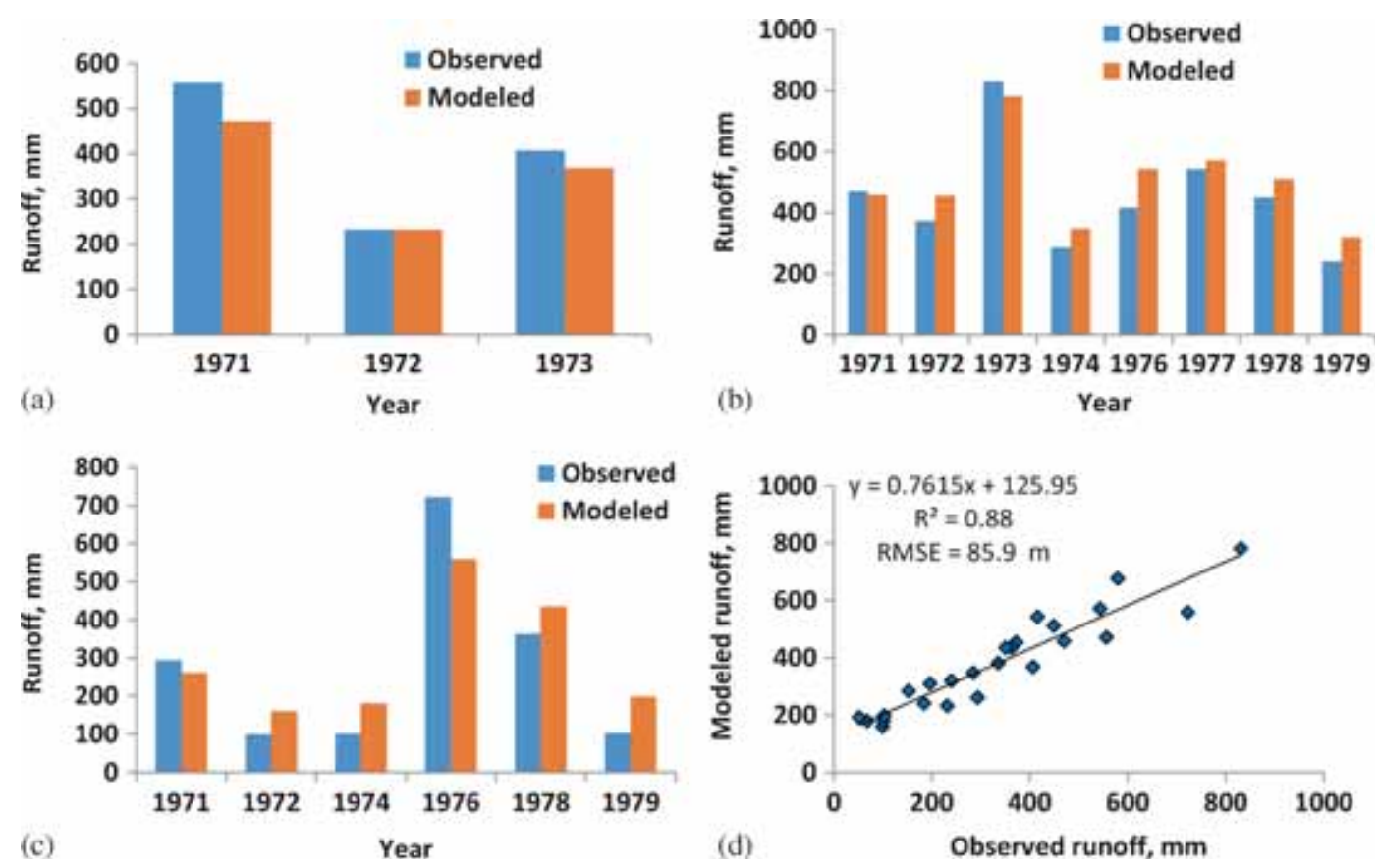

Figure 6. Comparison of observed run-off and modelled run-off for few river basins. (a) Ganga, (b) Narmada, (c) Mahi, and $(\mathbf{d})$ overall scatter plot.
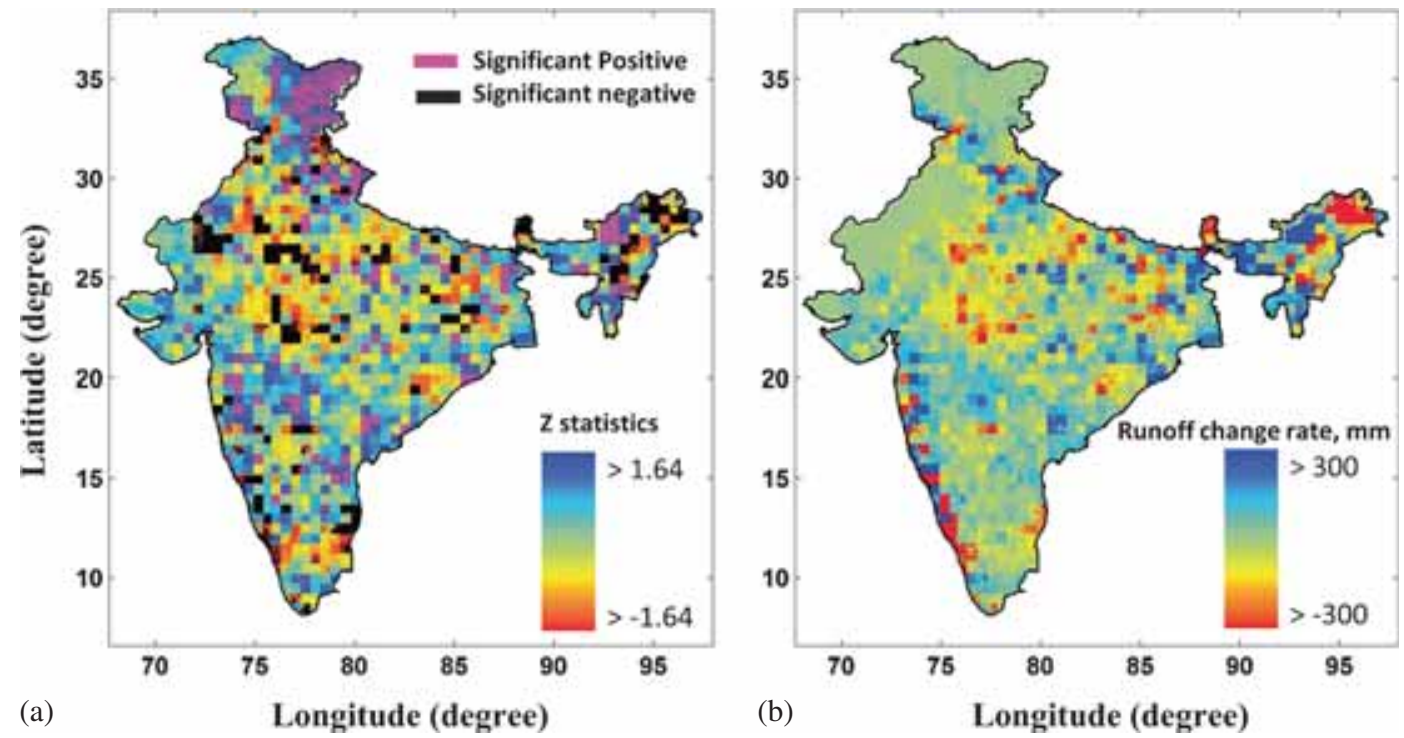

Figure 7. (a) Z statistics along with significant upward (positive) or downward (negative) trend of run-off and (b) rate of change (T) map of run-off (mm) over India considering 1971-2005.

(high frequency) in all the above-mentioned regions (Sugandh 2014), and this has attributed to the high rate of change and increasing trend of run-off. There was no significant trend of run-off over India as a whole but for various analysis windows, trends have been obtained and discussed in subsequent sections.

\subsubsection{Major river basins of India}

The temporal variations in seasonal run-off over major river basins in India for 1971-2005, revealed a significant decrease in the run-off pattern for the Cauvery and BKC4 basins, 11 more basins showed a decreasing trend but not statistically significant. The Mann-Kendall $Z$ statistic attained the values of -1.68 and -1.8 for these two basins and the trend was tested at $90 \%$ level of significance $(z=$ $\pm 1.64)$. The Theil Sen's Slope estimator showed a slope magnitude of 61.7 and $73.7 \mathrm{~mm}$ per year for Cauvery and BKC4, respectively. The remaining 15 basins indicated increasing trends of run-off, but none of them have significant trends at $90 \%$ level 
of significance. Details for major river basins are presented in table 1.

\subsubsection{Medium river basins of India}

It was observed that as the major river basins were sub-divided into medium river basins, the trend could be seen more significantly. An increasing trend was witnessed in 12 medium river basins at $90 \%$ level of significance (figure 8). The strength of the trend is quantified with their respective $Z$ values, which were highest in Kameng river and lowest in Ghagara d/s basins, and the rate of change was 477.0 and $199.4 \mathrm{~mm}$, respectively. Decreasing trend was witnessed in nine medium river basins (figure 8). The $Z$ value was highest in Tista upstream river basin and lowest in Chambal basin and the rate of change was -748.5 and $-81.2 \mathrm{~mm}$, respectively. In general, it has been observed that either the rainfall trend or the increase in the frequency of heavy rainfall events may be used for understanding the run-off trends. An overlay analysis of river basins with increasing trends of run-off, heavy rainfall frequency regions (Sugandh 2014) and flood-prone regions of India (National Disaster Management Authority, Govt. of India) suggests that there is a very good match among the layers for all the 12 river basins having positive run-off trends (Manneru, Kosi, Yamuna d/s, Ghaghra d/s, Kameng, Brahmaputra, Sabansiri, Kali, Minor basin-24, Jhelum d/s, Shyok, Godavari) and vice versa for nine river basins with negative trends (Amravati, Kuppam-1, Dhassan d/s, Chambal, Banas, Luni $\mathrm{u} / \mathrm{s}$, Tista $\mathrm{u} / \mathrm{s}$, Lohit and Siang). An understanding of the hydrological response of a river basin in the long term would help solve problems associated with upstream and downstream dynamics to address drought, floods, allocation of water for various sectors, etc. High or low run-off changes would influence the surface water availability, soil moisture and groundwater recharge, and would affect the frequency of droughts and floods.

Pettitt's test was applied to 28 river basins of India. The results of the analysis are summarised in table 2. It can be seen that five river basins (namely Chaliyar, Banas, Luni upstream, Nk3 and Tista upstream) showed an abrupt decreasing change while six river basins (Kosi, Brahmaputra, Nk5, Jhelum downstream, Satluj upstream and Godavari) showed an abrupt increase. Most of the abrupt changes occur at 13-15 time points, i.e., around mid-80s. The 18 other river basins did not show any statistically significant identifiable change point.

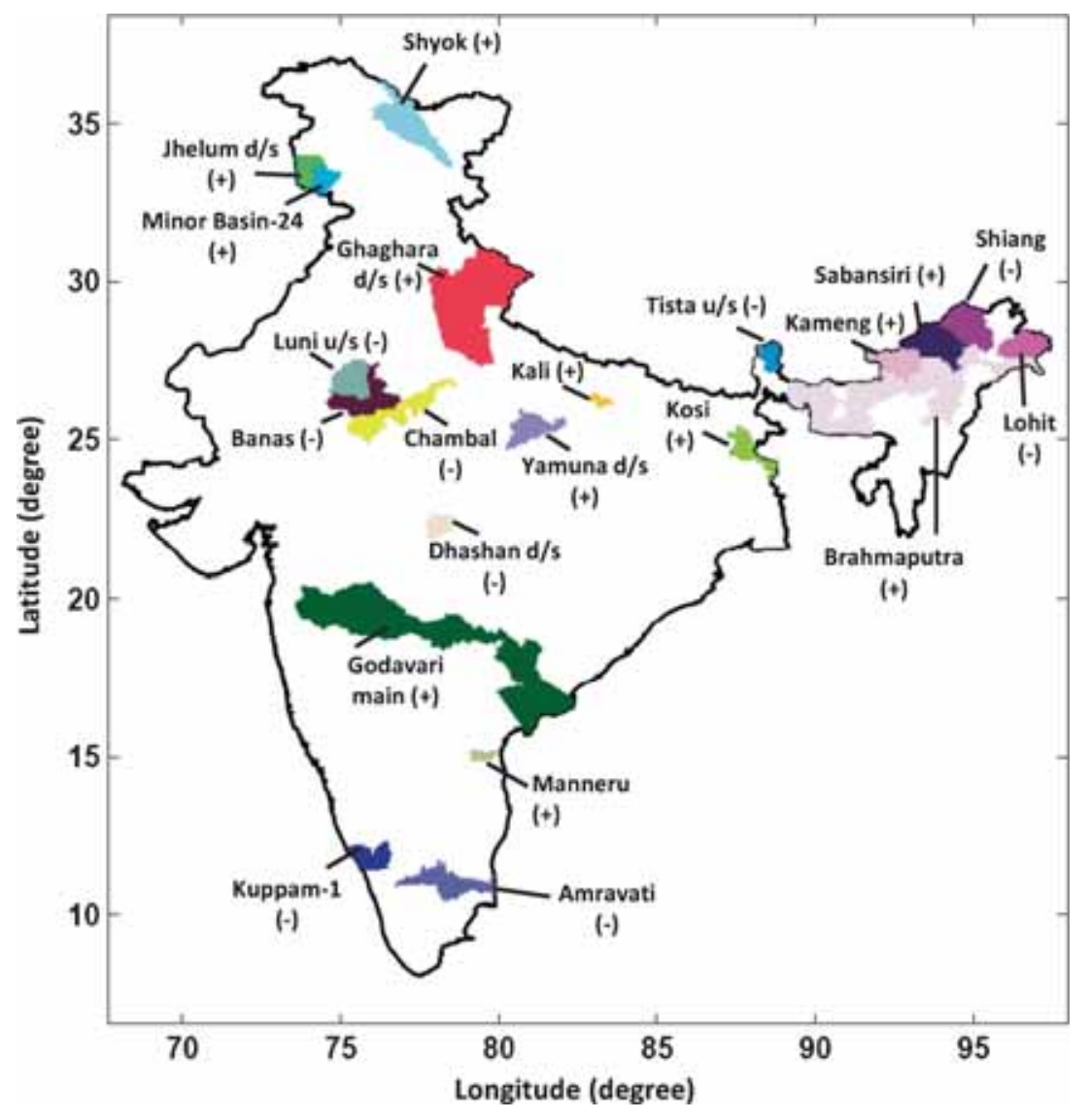

Figure 8. Medium river basins with significant positive and negative run-off trends. 


\subsubsection{Met subdivisions of India}

An equal number of meteorological subdivisions have shown increasing (17 subdivisions) or decreasing (17 subdivisions) trends albeit not statistically significant. But, a significant positive trend was observed in three meteorological subdivisions, viz., Assam and Meghalaya, Uttarakhand and J\&K while no significant decreasing trend was observed in the remaining subdivisions. The Theil Sen's slope estimator showed a rising slope magnitude in these divisions with run-off increase 226.1, 109.3 and $25.4 \mathrm{~mm}$ for Assam and Meghalaya, Uttarakhand and J\&K, respectively. Details for met-subdivisions are presented in table 1. Two meteorological subdivisions Assam and Meghalaya and J\&K showed increasing change at 90\% significance level with change point at 16 (1986) and 14 (1984), respectively whereas meteorological subdivision Uttarakhand did not show any statistically significant identifiable change point.

\subsubsection{Agro-climatic regions of India}

Average seasonal run-off during the study period contrasts from 60.3 (Western Dry Region, standard

Table 2. Pittett test details for medium river basins.

\begin{tabular}{|c|c|c|}
\hline Sl. no. & River names & $\begin{array}{l}\text { Break point, level of } \\
\text { significance \& trend }\end{array}$ \\
\hline 1 & Vaigai & NS \\
\hline 2 & Chaliyar & $11,10 \%$ \& decreasing \\
\hline 3 & Kaveri Tributary-Amravati & NS \\
\hline 4 & Kuppam-1 & NS \\
\hline 5 & Godavari Tributary-Manjra & NS \\
\hline 6 & Tapi Downstream & NS \\
\hline 7 & Dhasan Downstream & $\mathrm{NS}$ \\
\hline 8 & Kosi & $15,10 \%$ \& increasing \\
\hline 9 & Son & $\mathrm{NS}$ \\
\hline 10 & Sind & NS \\
\hline 11 & NK2 & NS \\
\hline 12 & Gomti & NS \\
\hline 13 & Banas & $13,5 \%$ \& decreasing \\
\hline 14 & Luni Upstream & $13,5 \%$ \& decreasing \\
\hline 15 & NK3 & $16,1 \%$ \& decreasing \\
\hline 16 & Tista Upstream & $16,1 \%$ \& decreasing \\
\hline 17 & Brahmaputra Tributary 3 & $\mathrm{NS}$ \\
\hline 18 & Brahmaputra & $16,10 \%$ \& increasing \\
\hline 19 & Sabansiri & $\mathrm{NS}$ \\
\hline 20 & Kali & $\mathrm{NS}$ \\
\hline 21 & Nk5 & $14,1 \%$ \& increasing \\
\hline 22 & Jhelum Downstream & $14,1 \%$ \& increasing \\
\hline 23 & Shyok Tributary 1 & $\mathrm{NS}$ \\
\hline 24 & Shyok & NS \\
\hline 25 & Satluj Upstream & $14,10 \%$ \& increasing \\
\hline 26 & Indus & NS \\
\hline 27 & Godavari main river & $17,10 \%$ \& increasing \\
\hline
\end{tabular}

NK: not known; NS: not significant. deviation $162.1 \mathrm{~mm}$ ) to $1008 \mathrm{~mm}$ (West Coast Plains and Hills Region, standard deviation $31.5 \mathrm{~mm}$ ). Analysis of trend parameters such as $Z$ statistics indicated increasing trends in half of the total 14 agro-climatic regions with a significant increase in the Western Himalayan regions whereas a decreasing trend was obtained for the rest half of the agro-climatic regions, but none has shown a significant decreasing trend. The magnitude of the run-off change varies from -68.7 to $54.1 \mathrm{~mm}$ for Central Plateau and Hills Region and Lower Gangetic Plain Region, respectively, considering the study period. Pittet test results showed an increasing change of rainfall based run-off at $95 \%$ significance level with change point at 17 (1987) for the Western Himalayan region. In India, where agriculture has a significant influence on both the economy and livelihood, the availability of sufficient water under changed climatic scenarios is vital. Therefore, trends in the surface water availability may be useful for managing the rainfed and irrigated systems through water conservation.

\subsubsection{Elevation zones of India}

In most of the elevation zones, there is an increasing trend of run-off as we progress from low to high altitudes. The run-off trend was found to be insignificant in the major elevation zones of India at $90 \%$ confidence level. Although an increasing trend of run-off was observed for the elevation zones from 300 to $1000 \mathrm{~m}$, afterwards rainfall and run-off both decreased abruptly. Also, it has been noticed that run-off for the low $(<200 \mathrm{~m}$; run-off $515.9 \mathrm{~mm})$ and high altitude (>1000 $\mathrm{m} ; 231.3 \mathrm{~mm})$ regions are not fitting with the trend (increasing from 300 to $460 \mathrm{~mm}$ ) which has been obtained for the regions falling between them for the increment of every $100 \mathrm{~m}$. The run-off trend was found to be insignificant in the major elevation zones of India at $90 \%$ confidence level.

\section{Conclusions}

The present study analysed rainfall data for the 35 years (1971-2005) and used to estimate the run-off generated at the national scale at $5 \times 5 \mathrm{~km}$ grid cell. Trend analysis was done over India as well as for various analysis windows such as medium and major river basins, met-subdivisions and elevation zones to determine the significance of the run-off and its trends. The following conclusions can be drawn from the study:

1. Average rainfall over India was observed to be $1012.5 \mathrm{~mm}$ with $33.7 \%$ rainfall to run-off conversion when considering the monsoon period (May-October) for 35 years (1971-2005). 
2. An exponential model of the order of two degrees, developed between rainfall and runoff, proved that these two variables are strongly correlated with the $R^{2}$ value of 0.97 and RMSE of $8.31 \mathrm{~mm}$.

3. River basins run-off trends show a large variability. The seasonal analysis shows that, while there was a significant increasing trend in 12 medium river basins (highest rate of change $13.6 \mathrm{~mm}$ per year for Kameng basin and lowest change of $5.6 \mathrm{~mm}$ per year for Ghaghra d/s basin), the trend was negative in other nine basins (highest rate of change $-21.4 \mathrm{~mm}$ per year for Tista $\mathrm{u} / \mathrm{s}$ basin and lowest change of $-2.3 \mathrm{~mm}$ per year for Chambal basin). Further, the majority of the basins show neither an increasing nor a decreasing significant trend in the seasonal run-off. Also, an increasing trend was witnessed in three meteorological subdivisions and two major river basins (positive), while, no evidence of statistically significant trend was observed in the elevation zones of India.

4. In trend analysis studies, it was observed that as the size of the analysis window was reduced to a smaller scale, the trend was more prominent than at the larger scales. Therefore, for India as a whole, there was no trend for rainfall as well as run-off.

5. Trends in hydrological variable may be used for planning and management of hydrological and agricultural practices of the country.

Finally, while interpreting the results of trend analysis, the observations of Cohn and Lins are worth repeating: "that reported trends are real yet insignificant indicates a worrisome possibility: natural climatic excursions may be much larger than we imagine. So large, perhaps, that they render insignificant the changes, human-induced or otherwise, observed during the past century".

\section{References}

Beven J K 2000 Rainfall-runoff modelling: The Primer; John Wiley and Sons Ltd., ISBN: 0-471-98553-8.

Burges S J, Wigmosta M S and Meena J M 1998 Hydrological effects of land-use change in a zero-order catchment; J. Hydraul. Eng. 3 86-97.

Chaplot V A M and Bissonnais Y L 2003 Runoff features for interrill erosion at different rainfall intensities, slope lengths, and gradients in an agricultural loessial hillslope; Soil Sci. Soc. Am. J. 67 844-851.

Chatterjee C, Jha R, Lohani A K, Kumar R and Singh R 2001 Runoff curve number estimation for a basin using remote sensing and GIS; Asian Pacific Remote Sens. and GIS J. 14 1-7.

Chow V T, Maidment D R and Mays L W 1988 Applied Hydrology; McGraw-Hill, New York.
Gilbert R O 1987 Statistical methods for environmental pollution monitoring; Van Nostrand Reinhold, New York.

Gupta P K and Panigrahy S 2007 Spatio-temporal modeling of runoff potential regions of India integrating remote sensing data in GIS domain; Curr. Sci. 95(8) 1580-1587.

Gupta P K, Panigrahy S and Parihar J S 2011 Impact of climate change on runoff of the major river basins of India using Global Circulation Model (HadCM3) projected data; J. Indian Soc. Remote Sens., doi: 10.1007/s12524-011-0101-7.

Gupta P K, Punalekar S, Panigrahy S, Sonakia A and Parihar J S 2012 Runoff modeling in an agro-forested watershed using Remote Sensing and GIS; J. Hydrol. Eng. 17(8) $1255-1267$.

Haith D A, Mandel R and Wu R S 1996 Generalized watershed loading functions (GWLF model) version 2.0 user's manual.

Huang C H 1995 Empirical analysis of slope and runoff for sediment delivery from interrill areas; Soil Sci. Soc. Am. J. 59 982-990.

Jobin D I and Pultz T J 1997 Assessment of three hydrological models for use with remotely sensed inputs; Proc. Workshop on Applications of Remote Sensing in Hydrology, NASA Goddard Space Flight Center, Greenbelt, Md.

Kendall M G 1962 Rank Correlation Methods; 3rd edn, Hafner Publishing Company, New York.

Kite G W and Piteroniro A 1996 Remote sensing applications in hydrological modeling; Hydrol. Sci. J. 41(4) 561-591.

Kumar V, Jain S K and Singh Y 2010 Analysis of long-term rainfall trends in India; Hydrol. Sci. J. 55 484-496.

Lal M 2001 Climatic change - implications for India's water resources; J. Indian Water Resour. Soc. 21 101-119.

Mall R K, Gupta A, Ranjeet S and Rathore L S 2006 Water resources and climate change: An Indian perspective; Curr. Sci. 90(12) 1610-1626.

Mishra S K, Jain M K, Pandey R P and Singh V P 2005 Catchment area-based evaluation of the AMC-dependent SCSCN-based rainfall-runoff models; Hydrol. Process. 19(14) 2701-2718.

Mooley D A and Parthasarathy B 1984 Fluctuations of all India summer monsoon rainfall during 1871-1978; Climatic Change 6 287-301.

Oza M P and Kishtwal C M 2014 Spatial analysis of Indian summer monsoon rainfall; J. Geomatics 8(1) 40-47.

Pandey V K, Panda S N and Sudhakar S 2003 Curve number estimation from watershed using digital image of IRS-1D, LISS III; www.gisdevelopment.net.

Pettitt A K 1979 A non-parametric approach to changepoint detection; Applied Statistics 28(2) 126-135.

Rajeevan M and Bhate J 2009 A high resolution daily gridded rainfall dataset (1971-2005) for mesoscale meteorological studies; Curr. Sci. 96(4) 558-562.

Refsgaard J C and Storm B 1995 Computer models in watershed hydrology; (ed.) Singh V P, Water Resources Publications, Littleton, Colo., pp. 806-846.

Sarkar R P and Thapliyal V 1988 Climate change and variability; Mausam 39 127-138.

SCS 1986 Urban hydrology for small watersheds; Technical Release No. 55, Soil Conservation Service, USDA, Washington, DC.

Sen P K 1968 Estimates of the regression coefficient based on Kendall's $\tau$; J. Am. Stat. Assoc. 39 1379-1389.

Sharma T, Satya Kiran P V, Singh T P, Trivedi A V and Navalgund R R 2001 Hydrological response of watershed 
to landuse changes: Remote sensing and GIS approach; Int. J. Remote Sens. 22 2095-2108.

Sharpley A N and Williams J R 1990 EPIC - Erosion/ Productivity Impact Calculator: 1. Model Documentation; US Department of Agriculture Technical Bulletin No. 1768, US Government Printing Office: Washington, DC.

Singh V P, Frevert K and Donald 2006 Watershed Models; Taylor and Francis (CRC), ISBN 0-8493-3609-0.

Sinha Ray K C and De U S 2003 Climate change in India as evidenced from instrumental records; WMO Bull. 52 $53-59$.

Srivastava H N, Dewan B N, Dikshit S K, Prakash Rao G S, Singh S S and Rao K R 1992 Decadal trends in climate over India; Mausam 43 7-20.

Sugandh 2014 Modeling runoff and spatio-temporal pattern characterization of extreme rainfall events over the mainland of India; An unpublished B. Tech Thesis, College of Agricultural Information Technology, Anand Agricultural University, Anand, Gujarat, India.

Thapliyal V and Kulshreshtha S M 1991 Climate changes and trends over India; Mausam 42 333-338.

USDA 1986 Urban Hydrology for Small Watersheds, Technical Release 55, 2nd edn (Springfield, VA: United States Department of Agriculture Natural Resources Conservation Service), ftp.wcc.nrcs.usda.gov/downloads/ hydrology_hydraulics/tr55/tr55.pdf.

Vijay K, Jain S K and Singh Y 2010 Analysis of longterm rainfall trends in India; Hydrol. Sci. J. 55(4) 484-496.

Zade M R, Ray S S, Dutta S and Panigraphy S 2005 Analysis of runoff pattern for all major basins of India derived using remote sensing data; Curr. Sci. 88(5) 1301-1305.

MS received 15 October 2015; revised 27 April 2016; accepted 12 May 2016

Corresponding editor: Subimal Ghosh 